\title{
Model Quadruple Helix dalam Pengembangan UMKM (Studi Kasus Pada Industri Pisang Sale Kutacane Kab. Aceh Tenggara)
}

\author{
Muslim Marpaung ${ }^{1)}$, Sugianto ${ }^{2)}$, Ulfa Yolanda ${ }^{3 *}$ \\ 1,2,3 Fakultas Ekonomi dan Bisnis Islam, Universitas Islam Negeri Sumatera Utara, Medan \\ *Email Korespondensi: ulfayolanda25@gmail.com
}

\begin{abstract}
This study aims to obtain a comprehensive picture of the synergy of banana sale stakeholders in Kab. Southeast Aceh. The Quadruple Helix model is one suitable model for social research and innovation. This study uses a qualitative research design with a phenomenological approach that seeks to understand the perspectives, thoughts and experiences of stakeholders regarding the synergy of Quadruple Helix stakeholders in realizing the development of the banana sale business in Kab. Southeast Aceh. The results show that there are a number of problems related to synergy in the development of banana sale in Kab. Aceh Tenggara is partly because there is no common vision of stakeholders and cooperation and coordination between banana sale business actors, the government and stakeholders. Each stakeholder translates the sale of bananas, causing a debate on how to develop the sale of bananas in the future. In particular, the government should pay special attention to banana sale managers equally to develop the banana sale business and support from the wider community. The key to the successful implementation of the banana sale business development in Kab. Aceh Tenggara, among others, unity of mission, joint commitment and coordination among stakeholders.
\end{abstract}

Keywords: Banana sale, synergy, stakeholders, Quadruple Helix.

Saran sitasi: Marpaung, M., Sugianto., \& Yolanda, U. (2021). Model Quadruple Helix dalam Pengembangan UMKM (Studi Kasus Pada Industri Pisang Sale Kutacane Kab. Aceh Tenggara). Jurnal Ilmiah Ekonomi Islam, 7(02), 891-899. doi: http://dx.doi.org/10.29040/jiei.v7i2.2615

DOI: http://dx.doi.org/10.29040/jiei.v7i2.2615

\section{PENDAHULUAN}

Kemajuan suatu usaha ditentukan oleh banyak faktor dan peran berbagai pihak. Usaha Mikro Kecil dan Menengah (UMKM) mempunyai peran penting dalam pembangunan ekonomi, karena dapat memperluas lapangan kerja dan memberikan pelayan ekonomi kepada masyarakat secara luas. UMKM bisa menyesuaikan kondisi pasar yang terus berubah-ubah dari waktu ke waktu, oleh karena itu UMKM tidak rentan terhadap perubahan eksternal dan mampu menampung berbagai macam peluang untuk tenaga kerja tersebut. Adapun jumlah pelaku usaha UMKM di Indonesia pada tahun 2018 sebanyak 58,97 juta orang, sedangkan jumlah penduduk di Indonesia pada tahun 2018 dipediksi mencapai 265 juta jiwa (Https://Keuangan.Kontan.Co.Id, 2020).

Perkembangan Data Usaha Mikro, Kecil, Menengah (UMKM) di Indonesia tahun 2015-2018 (Http://Www.Depkop.Go.Id/Data-Umkm, 2021):

\begin{tabular}{|c|c|c|c|c|c|}
\hline No & Tahun & Satuan & $\begin{array}{c}\text { Usaha } \\
\text { Mikro } \\
\text { (UMi) }\end{array}$ & $\begin{array}{c}\text { Usaha } \\
\text { Kecil } \\
\text { (UK) }\end{array}$ & $\begin{array}{c}\text { Usaha } \\
\text { Menengah } \\
(\mathbf{U M})\end{array}$ \\
\hline 1 & 2015 & Unit & 58.521 .987 & 681.522 & 59.263 \\
\hline 2 & 2016 & Unit & 60.863 .578 & 731.047 & 56.551 \\
\hline 3 & 2017 & Unit & 62.106 .900 & 757.090 & 58.627 \\
\hline 4 & 2018 & Unit & 63.350 .222 & 783.132 & 60.702 \\
\hline
\end{tabular}

Wakil gubernur Aceh Nova Irwansyah dalam acara Peringatan Hari Usaha Mikro Kecil Menengah Internasional pada tahun 2018, mengatakan bahwa Aceh kaya salah satu dari 15 program pokok pemerintah Aceh mendukung dan memperkuat sektor UMKM di Aceh. Anggaran disiapkan mencapai Rp. 166,8 miliar yang bersumber dari APBD pada tahun 2018. Berdasarkan data tahun 2016, jumlah UMKM di Aceh mencapai 75.207 unit, meningkat pesat jika dibandingkan tahun 2014 yang hanya sebesar 48.882 unit. Pada umumnya UMKM ini bergerak dalam 
bidang perdagangan, jasa, pertanian, pertambangan, industri, perikanan, transportasi dan peternakan

UMKM di Kutacane, Kab. Aceh Tenggara bergerak diberbagai bidang antara lain seperti kelontong, pengelola pisang sale, grosir sembako, warkop, jualan kain, jualan pakaian, jualan kain, bahan konveksi, jualan gorden, jualan emas, jualan kompilasi, warkop, dan lain sebagainya. Kutacane, Kab. Aceh Tenggara dikelilingi oleh daerah pengunungan dan menjadi sumber penghidupan masyarakat sekitar pada umumnya, karena wilayah pengunungan ini memiliki berbagai macam sumber daya alam serta jasa lingkungan yang dijadikan sumber penghidupan. Adapun salah satu hasil dari gunung itu adalah menanam pohon pisang yang dapat diolah menjadi pisang sale. Kegiatan pengolahan pisang sale ini masih tergolong industri rumah tangga, termasuk golongan usaha kecil atau menengah. Dengan adanya usaha kecil akan mampu menyerap tenaga kerja dan bisa menghasilkan produk dengan harga yang terjangkau untuk memenuhi kebutuhan masyarakat

(Http://Datakumkm.Acehprov.Go.Id/Index.Php/Umk $m, 2021)$.

Adapun jumlah pengelola pisang sale di Kab. Aceh Tenggara sebagai berikut:

\begin{tabular}{|c|l|c|}
\hline No & \multicolumn{1}{|c|}{ Kecamatan } & $\begin{array}{c}\text { Pengelola } \\
\text { Pisang Sale }\end{array}$ \\
\hline 1 & Kecamatan Babul Makmur & 62 \\
\hline 2 & Kecamatan Babussalam & 46 \\
\hline 3 & Kecamatan Ketambe & 20 \\
\hline 4 & Kecamatan Deleng Pokisen & 35 \\
\hline 5 & Kecamatan Bambel & 30 \\
\hline 6 & Kecamatan Babul Rahmah & 32 \\
\hline 7 & Kecamatan Badar & 28 \\
\hline & Jumlah & 253 \\
\hline
\end{tabular}

Sumber: Hasil wawancara bersama Ibu Mira Wati Staff di Kantor Dinas UKM dan Koperasi Kab. Aceh Tenggara.

Dari hasil wawancara dengan Ibu Mira Wati ia menggatakan bahwa terdapat 253 orang pengelola yang ada di Kutacane. Oleh karena itu, salah satu pengolahan pisang sale terdapat di Desa Tanoh Alas Kec. Babul Makmur Kab. Aceh Tenggara. Pengolahan pisang sale ini setiap minggu diproduksi oleh produsen, tetapi produsen masih mengalami kesulitan untuk memasarkan pisang sale. Dari segi pemasaran masalah yang timbul seperti proses pemasaran pisang sale bersifat tradisional yaitu penjual hanya berharap kepada pembeli yang akan datang langsung dan pengelola pisang sale menjual eceran kepada agen-agen yang lain tetapi masih relatif sedikit dan hanya bisa didapatkan di Lawe Pakam perbatasan antara Aceh dan Kabupaten Karo.

Pendekatan quadruple helix diperkenalkan oleh Carayanis dan Campbell pada tahun 2009, menekankan bahwa interaksi keempat komponen ABCG (Academia, Business, Community, Goverment) merupakan kunci utama bagi peningkatan kondisi yang kondusif bagi lahirnya UMKM (Praswati, 2017).

Kemajuan industri pisang sale ini seharusnya jangan disia-siakan oleh pemerintah. Pemerintah perlu memfasilitasi dengan menyediakan pasar dan faktorfaktor produksi. Kebijakan-kebijakan ekonomi yang diambil juga hendaknya berpihak pada kemajuan pisang sale dengan memberikan kepada pengelola pisang sale khususnya yang ada di Kab. Aceh Tenggara (Barus, 2019). Oleh karena itu, dalam penelitian ini penulis menawarkan konsep Quadruple Helix (akademisi, pemerintah, bisnis, komunitas) yang diharapakan kedepannya ada perubahan yang belum berjalan secara baik meski telah disusun kurikulum pelatihan bagi UMKM.

Dari uraian diatas mendorong penulis mengadakan penelitian lebih lanjut dengan penelitianpenelitian sebelumnya hanya berfokus kepada UMKM. Melihat kenyataan tersebut, penulis tertarik melakukan penelitian tentang pengembangan usaha mikro kecil menengah (UMKM) menggunakan model Quadraple Helix (studi kasus pada industri pisang sale di Kab. Aceh Tenggara.

\section{METODE PENELITIAN}

\subsection{Pendekatan dan Metode Penelitian}

Penulis menggunakan metode penelitian jenis kualitatif. Metode penelitian kualitatif merupakan metode penelitian yang sangat memfokuskan pada aspek pemahaman secara mendalam terhadap suatu masalah daripada melihat permasalahan untuk penelitian generalisasi (Moelong, 2016). Penelitian ini menggunakan desai penelitian kualitatif dengan pendekatan fenomenologi yang berusaha memahami perspektif, pemikiran, dan pengalaman para pemangku kepentingan terkait sinergi stakeholder Quadruple Helix.

\subsection{Lokasi Penelitian}

Penelitian ini dilakukan di Kutacane Kab. Aceh Tenggara untuk akademisi akan dilakukan di STAISES Kutacane, Para pelaku UMKM pengelola pisang sale di kota Kutacane Desa Tanoh Alas Kec. 


\section{Jurnal Ilmiah Ekonomi Islam, 7(02), 2021, 893}

Babul Makmur, Kab. Aceh Tenggara, kemudian di Dinas Koperasi dan UMKM Kota Kutacane Jl. Ahmad Yani, Dinas Perdagangan, Dinas Perindustrian.

\subsection{Teknik Pengumpulan Data}

Penelitian ini menggunakan tiga teknik pengumpulan data yaitu:

\subsubsection{Observasi}

Merupakan suatu cara untuk mendapatkan data atau informasi dengan tanya jawab secara langsung pada pihak yang mengetahui tentang objek yang diteliti. Dalam hal ini adalah pihak atau pegawai Usaha Mikro Kecil dan Menengah (UMKM) ada di Kutacane yang terdaftar di Dinas Koperasi dan UMKM Kutacane.Wawancara dilakukan oleh peneliti, guna untuk mencari data atau informasi yang digunakan sesuai dengan judul pada penelitian ini (Sugiyono, 2018).

\subsubsection{Wawancara}

Dalam melakukan teknik pengumpulan data yang digunakan oleh peneliti adalah wawancara terstruktur yaitu mendapatkan infomasi untuk mencapai tujuan penelitian, maka peneliti melakukan tanya jawab dan bertatap muka dengan para stakeholder (Sugiyono, 2018).

\subsubsection{Dokumentasi}

Studi dokumen adalah suatu metode pengumpulan data yang digunakan dalam metodologi penelitian sosial. Metode dokumentasi digunakan untuk mencari dokumen-dokumen pengelola pisang sale di Kutacane Kabupaten Aceh Tenggara (Sugiyono, 2018).

\section{HASIL DAN PEMBAHASAN}

\subsection{Hasil Penelitian}

\subsubsection{Sejarah Pisang Sale di Kab. Aceh Tenggara}

Kab. Aceh Tenggara memiliki 16 Kecamatan, yaitu Lawe Alas, Lawe Sigala-gala, Bambel, Babussalam, Badar, Babul Makmur, Darul Hasanah, Lawe Bulan, Bukit Tusam, Semadam, Babul Rahmah, Ketambe, Deleng Pokisen, Lawe Sumur, Tanoh Alas, Lauser. Pisang sale awal mulanya menjadi oleh-oleh khas Aceh, karena pada zaman dahulu pisang sale sangat berlimpah di Aceh. Sehingga masyarakat berinisiatif untuk mengolah pisang tersebut sebagai makanan ringan masyarakat Aceh serta menjadikan makanan yang dihidangkan pada saat ada tamu yang datang kerumah masyarakat setempat (Www.Bps.Go.Id, 2021).
Dari almarhum Peutua Hasan dan Pang Puteh inilah ide pertama mengawetkan pisang monyet (pisang wak), yaitu pada tahun 1937, jauh dari sebelum Indonesia merdeka. Saat itu Desa Geudumbak yang penduduknya masih dapat dihitung dengan jari, merupakan perkampungan baru dengan kondisi pisang monyet bertumbuhan secara liar. Pada saat panen tiba, jutaan tandan pisang mengalami masak serentak, jangankan manusia, monyetmonyetpun minta ampun tidak sanggup untuk menyantapnya. Dari situlah muncul ide, pisang masak tersebut diasapi (disale, bahasa Aceh), dibungkus dan dijual dalam bentuk kemasan tradisional.

Asal mula pisang sale di Kutacane Kab. Aceh Tenggara, sebagaimana diungkapkan oleh Ibu Mira sebagai salah satu pengelola pisang sale mengatakan awalnya pisang sale ini benar turun menurun bisa dikatakan budaya dari orang tua kita terdahulu, akan tetapi Ibu Mira tekuni pada saat tidak memiliki penghasilan. Sebelum mengelola pisang sale, Ibu Mira bekerja sebagai pembantu rumah tangga, setelah itu posisi rumah Ibu Mira berhadapan dengan salah satu PONPES Perbatasan di Kab. Aceh Tenggara, Ibu Mira menyuci pakaian beberapa santri/santriwati tersebut.

\subsubsection{Analisis Pengembangan Usaha Pisang Sale di Kab. Aceh Tenggara}

Mengembangkan suatu usaha, terdapat banyak hal yang harus diterapkan dan menjadi langkahlangkah yang harus dijalankan oleh suatu perusahaan untuk mencapai suatu tujuan. Dalam mencapai suatu tujuan, langkah yang harus dihadapi bersifat terjal dan berlika-liku, akan tetapi ada juga langkah yang relatif mudah. Oleh karena itu banyak rintangan atau cobaan yang dihadapi untuk mencapai suatu tujuan, maka setiap langkah harus dijalankan secara hati-hati dan terarah.

Keberadaan industri kecil di lingkungan masyarakat memiliki peran yang cukup besar seperti menyerap tenaga kerja di lingkungan masyarakat yang menghasilkan produk yang dibutuhkan dan mengembangkan suatu kratifitas. Salah satu manfaat pisang sale di Kab. Aceh Tenggara yaitu menambah pendapatan masyarakat sekitar dan secara tidak langsung dapat meningkatkan taraf hidup.

Pengembangan usaha pisang sale di Kab. Aceh Tenggara sangat memiliki kaitan yang erat terhadap stakeholder Quadruple Helix (Akademisi, Pemerintah, Bisnis, Komunitas) yaitu: 


\section{Jurnal Ilmiah Ekonomi Islam, 7(02), 2021, 894}

\section{a. Akademisi}

Akademisi pada model Quadruple Helix berperan sebagai konseptor, pembuat ide-ide dan inovasi-inovasi baru untuk dijalankan stakeholder lainnya. Seperti melakukan standarisasi proses bisnis serta sertifikasi produk dan keterampilan sumber daya manusia. Akademisi dalam hal ini merupakan sumber pengetahuan dengan konsep, teori-teori terbaru dan relavan dengan bisnis yang dikembangkan pelaku UMKM untuk mendapatkan keunggulan kompetitif yang berkelanjutan. Sehigga peran akademisi disini berbagi informasi dengan pelaku UMKM.

Akademisi dalam hal ini pihak universitas atau perguruan tinggi terutama perguruan tinggi yang berada di daerah tersebut. Akademisi juga bertanggung jawab menjadi pengkaji arah pengembangan usaha pengelola pisang sale di Kab. Aceh Tenggara, mengkaji kebijakan-kebijakan yang perlu stakeholder lainnya serta mengkaji regulasiregulasi yang dianggap penting dan tepat dalam pengembangan usaha pengelola pisang sale di Kab. Aceh Tenggara. Peran perguruan tinggi juga dilakukan melalui pelatihan dan kursus bagi pelaku usaha dan masyarakat, melakukan pemetaan potensi, identifikasi permasalahan, rumusan strategi dan penyuluhan, sosialisasi dan pembentukan kelompok binaan.

\section{b. Pemerintah}

Pemerintah pada model Quadruple Helix berperan sebagai regulator. Pemerintah berperan sebagai regulator sekaligus berperan sebagai kontroler yang memiliki peraturan dan tanggung jawab dalam mengembangkan usaha. Pemerintah juga memiliki peran dalam mengkoordinasi para pemangku kepentingan yang berkontribusi pada pengembangan UMKM di Kutacane Kab. Aceh Tenggara. Dalam pemgembangan UMKM Kutacane, Kab. Aceh Tenggara yang memiliki peran sebagai pemerintah adalah tenaga kerja, kementrian perindustrian, Koperasi dan UKM dan dinas Perdagangan. Pemerintah berperan sebagai regulator sekaligus sebagai kontroler yang memilki peraturan dan tanggung jawab dalam mengembangkan usaha. Dalam hal ini melibatkan semua jenis kegiatan seperti, perencaaan, pelaksanaan, pemantauan pengendalian, promosi, perizinan, alokasi keuangan, program, Undang-Undang, pengembangan dan pengetahuan, kebijakan inovasi publik, dukangan untuk jaringan inovasi dan kemitraan pintar usaha pengelola pisang sale. Pemrintah juga memiliki peran dalam mengkoordinasi para pemangku kepentingan yang berkontribusi pada pengembangan usaha pengelola pisang sale.

\section{c. Bisnis}

Bisnis pada model Quadruple Helix berperan sebagai enabler. Yang dimaksud degan enabler dalam penelitian ini adalah pembisnis menjadi stakeholder yang membantu dalam mencapai tujuan yang diinginkan. Bisnis merupakan entitas yang melakukan proses bisnis dalam menciptakan nilai tambah dan mempertahankan pertumbuhan yang berkelanjutan. Bisnis berperan sebagai enabler menghadirkan infrastruktur pengelola pisang sale yang dibutuhkan, terutama dalam hal ini kebutuhan dari pihak pengelola pisang sale. Sektor swasta merupakan entitas yang melakukan proses bisnis dalam menciptakan nilai tambah dan mempertahankan pertumbuhan yang berkelanjutan. Sektor swasta dapat berperan sebagai enabler menghadirkan infrastruktur teknologi dan modal. Dengan adanya perubahan ke era digital maka dapat membantu pengembangan potensi pengelola pisang sale menjadi lebih efektif, efesien dan produktif. Dalam program pengembangan UMKM yang memiliki peran sebagai bisnis.

\section{d. Komunitas}

Komunitas pada model Quadruple Helix berperan sebagai akselerator. Dalam hal ini komunitas merupakan orang-orang yang memiliki minta yang sama dan relevan dengan bisnis yang berkembang. Bertindak sebagai perantara atau menjadi penghubung antar pemangku kepentingan untuk membantu UMKM dalam keseuruhan proses dan mempelancar adopsi proses bisnis ke era digital komunitas juga memiliki peran untuk mempromosikan produk atau layanan UMKM. Dalam program pengembangan UMK di Kab. Aceh Tenggara memiliki peran sebagai komunitas yang menaungi UMKM.

Para-para komunitas di Kab. Aceh Tenggara sangat banyak sudah memulai dengan beberapa tahapan diantaranya pengenalan produk dari komunitas yang bukan dibidang usaha seperti komunias sepeda dan motor yang ikut berpartisipasi mengembangkan usaha pisang sale dan mengupload ke masing-masing media sosial mereka. selanjutnya komunitas yang berada digaris pelaku usaha dengan cara edukasi mengikuti pelatihan-pelatihan dalam perkembangan usaha pengelola pisang sale. 


\subsection{Pembahasan}

\subsubsection{Usaha Pisang Sale Sebagai Warisan Tradisi}

Krisis yang menimpa Indonesia pada tahun 1997, diawali dengan krisis nilai tukar rupiah terhadap dollar AS dan krisis moneter yang berdampak pada perekonomian Indonesia yakni resesi ekonomi. Hal ini merupan pelajara yang sangat penting untuk kembali mencermati guna untuk pembangunan ekonomi yang benar-benat struktur yang kuat dan dapat bertahan dalam situasi apapun (Anggraini \& Nasution, 2013). Peraturan Presiden No. 5 Tahun 2007 mengenai pembiayaan operasional UMKM, UU No. 20 Tahun 2008 tentang perbedayaan UMKM bagi oerekonomian di Indonesia, dan yang terbaru adalah Paket 4 Kebijakan Ekonomi "Kebijakaan Kredit Usaha Rakyat (KUR) yang lebih murah dan luas" bagi UMKM (Suci, 2017).

Pisang sale awal mulanya menjadi oleh-oleh khas Aceh, karena pada zaman dahulu pisang sale sangat berlimpah di Aceh. Sehingga masyarakat berinisiatif untuk mengolah pisang tersebut sebagai makanan ringan masyarakat Aceh serta menjadikan makanan yang dihidangkan pada saat ada tamu yang datang kerumah masyarakat setempat.

Dari almarhum Peutua Hasan dan Pang Puteh inilah ide pertama mengawetkan pisang monyet (pisang wak), yaitu pada tahun 1937, jauh dari sebelum Indonesia merdeka. Saat itu Desa Geudumbak yang penduduknya masih dapat dihitung dengan jari, merupakan perkampungan baru dengan kondisi pisang monyet bertumbuhan secara liar. Pada saat panen tiba, jutaan tandan pisang mengalami masak serentak, jangankan manusia, monyetmonyetpun minta ampun tidak sanggup untuk menyantapnya.

Dari situlah muncul ide, pisang masak tersebut diasapi (disale, bahasa Aceh), dibungkus dan dijual dalam bentuk kemasan tradisional. Oleh karena itu, pekerjaan itu sudah menjadi turun menurun, malah pengrajin generasi berikutnta sudah menjalar sepanjang kawasan bantaran sungai (Krueng Arakundo), Kec Pante Bdari Lhoknibong, Aceh Timur dan hitung-hitung dari ide Petua Hasan-Pang Puteh tersebut, kini sudah menampung ribuan tenaga kerja, terhitung dari mata rantai produsen, pengumpul maupun pengencernya.

Asal mula pisang sale di Kutacane Kab. Aceh Tenggara, sebagaimana diungkapkan oleh Ibu Mira sebagai salah satu pengelola pisang sale mengatakan awalnya pisang sale ini benar turun menurun bisa dikatakan budaya dari orang tua kita terdahulu, akan tetapi saya tekuni pada saat saya tidak memiliki penghasilan. Sebelum mengelola pisang sale, saya bekerja sebagai pembantu rumah tangga, setelah itu posisi rumah saya berhadapan dengan salah satu PONPES Perbatasan di Kab. Aceh Tenggara, maka saya menyuci pakaian beberapa santri/santriwati tersebut.

Beriringnya waktu, abang saya menawarkan kepada saya untuk mengelola pisang yang ada di kebun abang saya. Tetapi saya bingung, karena saya belum pernah mengelola pisang menjadi pisang sale. Akan tetapi solusi kami temukan, abang saya menelpon saudara yang ada di Banda Aceh, beliau di Banda Aceh membuat pisang sale juga. Setelah itu saya terapkan, Alhamdulillah, usaha pisang sale saya lancar sampai saat ini.

\subsubsection{Persepsi Quadruple Helix tentang UMKM Pengelola Pisang Sale di Kab. Aceh Tenggara}

Persoalan yang berkaitan dengan persepsi adalah merupakan cara tersendiri untuk mengetahui sebenarnya kemana arah dari pilihan stakeholder pada sebuah tujuan UMKM khususnya bagi pengelola pisang sale. Tidak hanya kualitas terhadap pisang sale, akan tetapi juga pandangan terhadap kebersihan, estetika, serta yang berkaitan dengan kondisi pisang sale tersebut. Tanpa diketahui bagaimana persepsi stakeholder terhadap berbagai aspek yang mesti tersedia dalam mendukung keberadaan UMKM pengelola pisang sale daerah tujuan bagi pengelola pisang sale, maka dalam jangka panjang kawasan tujuan UMKM pengelola pisang sale akan tumbuh sejalan dengan perkembangan sesungguhnya.

Dalam hal ini persepsi, akademisi di Kab. Aceh Tenggara sudah memahami tentang UMKM pengelola pisang sale, meskipun belum sepenuhnya memahami tentang UMKM pengelola pisang sale tersebut. Namun disisi lain persepsi mereka tentang UMKM pengelola pisang sale masih mengusung persepsi masing-masing. Sehingga belum ada kesamaan persepsi diantara stakeholder. Hal ini membuat para akademisi belum bisa menarik garis tentang apa dan bagaimana sebenarnya UMKM pengeola pisang sale dijalankan. Hal yang sama dilontarkan persepsi UMKM pengelola pisang sale dikalangan pemerintah. Umumnya pemerintah juga sudah membantu pihak pengelola pisang sale khususnya dari kantor dinas UKM dan Koperasi di Kab. Aceh Tenggara, akan tetapi di kantor Dinas 


\section{Jurnal Ilmiah Ekonomi Islam, 7(02), 2021, 896}

Industri dan Perdagangan belum ada perhatian khusus terhadap pelaku pengelola pisang sale di Kab. Aceh Tenggara.

Persepsi stakeholder selanjutnya adalah dari bisnis, para pelaku pebisnis pengeloa pisang sale di Kab. Aceh Tenggara juga mempunyai pandangan yang berbeda dengan stakeholder lainnya. Para pelaku pengelola pisang sale berharap ada perhatian khusus dan pihak pemerintah terhadap pengelola pisang sale, akan tetapi perhatian yang didapatkan oleh pengelola pisang sale hanya dari pihak Dinas UKM dan Koperasi saja, akan tetapi tidak merata perhatiannya kepada pengelola pisang sale, didapatkan informasi dari salah satu pengelola pisang sale:

\subsubsection{Peran dan Usaha Stakeholder dalam Pengembangan Usaha pisang Sale di Kab. Aceh Tenggara}

Akademisi berperan sebagai mendukung untuk memasarkan pisang sale kepada masyarakat dan akademisi juga berperan mempromosikan pisang sale ke sosial media. Karena pengelola pisang sale khususnya Kab. Aceh Tenggara belum menggunakan sosialkan media untuk mempromosikan pisang sale tersebut disebabkan kurangnya pengetahuan pengelola pisang sale dan juga sebagian besar pengelola pisang sale ini tidak mempunyai $\mathrm{hp}$ android karena latar belakang mereka sebagian di perdesaan. Akan tetapi, ada juga pengelola pisang sale menggunakan hp android maupuan anak mereka, tapi belum ada yang mempromosikannya di sosial media seperti facebook, instagram, whatshaap, maupun marketplace lainnyaa.

Peran dan usaha pemerintah diantaranya adalah Dinas UKM dan Koperasi Kab. Aceh Tenggara, telah berusaha dalam pengembangan UMKM khususnya pengelola pisang sale. Dengan cara mengutuskan pengeloa pisang sale ke Banda Aceh apabila ada pelatihan, tujuannya adalah di Banda Aceh saat pelatihan pengelola pisang sale ini diajarkan bagaimana memasak pisang sale agar renyah, membungkus pisang sale dengan cara cepat dan tepat, banyak ilmu yang didapat oleh pengelola pisang sale pada saat pelatihan di Banda Aceh.

Menurut pembisnis atau pengusaha, peran mereka adalah turut memberikan kualitas produk yang terbaik kepada masayarakat. Dan ada saran kepada pengelola pisang sale, untuk saat ini kita mengetahui bahwa produk pisang sale yang dipasarkan masih bersifat original dari pisang saja, kedepannya bisa diproduksi berbagai macam varian rasa pisang sale, seperti pisang sale coklat, pisang sale tiramisu dan beragai macam varian rasa untuk pisang sale tersebut. Sedangkan komunitas adalah membantu pemerintah dalam sosialisasi pisang sale kepada masyarakat dan bersama pemerintah juga memberikan ide-ide tentang memasarkan produk pisang sale.

\subsubsection{Faktor-faktor Pendukung dan Penghambat Pengembangan Usaha pisang Sale di Kab. Aceh Tenggara}

Aceh Tenggara sudah selayaknya mengambil peran yang lebih besar dalam menerapkan dan mengembangkan UMKM khususnya bagi pengelola pisang sale. Karena sudan menjadi "gen" Aceh Tenggara menerapkan UMKM khususnya pengelola pisang sale untuk memenuhi keberlangsungan masyarakat.

Dalam pandangan penulis sebenarnya pengembangan UMKM pengelola pisang sale di Kab. Aceh Tenggara bukannya tidak ada, namun masih jalan ditempat karena sedang dalam proses dan proses ini lebih kepada regulasi dan persepsi yang belum satu, sehingga semuanya saling menunggu. Harus ada yang menggerakkan ini semua dengan cara sosialisasi dan edukasi yang komprehenship dari stakeholder terkait, agar pelaksanaan UMKM pengelola pisang sale bisa dipahami dan sama-sama bisa menjankan dan mengembangkannya.

\subsubsection{Sinergitas antar Stakeholder Quadruple Helix}

Adanya interaksi antar ketiga stakeholder selain itu juga diperlukan adanya sinergi antar keempat stakeholder Quadruple Helix. Mengartikan sinergi sebagai kombinasi atau panduan untur atau bagian yang dapat menghasilkan keluaran lebih baik dan lebih besar. Jadi sinergi dapat dipahami sebagai operasi gabungan atau perpaduan unsur untu menghasilkan output yang lebih baik (Najiyati, 2011). Sinergitas dapat terbagun melalui cara yaitu, pertama, komunikasi, pengertiam komunikasi dapat dibedakan atas dua bagian yaitu komunikasi yang berorientasi pada sumber menyatak an bahwa, komunikasi adalah kegiatan dengan mana seorang (sumber) secara sungguh-sungguh memindahkan stimuli guna mendapatkan tanggapan, kedua, pengertian komunikasi yang berorientasi pada penerima memandang bahwa, komunikasi sebagai semua kegiatan dimana seseorang (penerima) menanggapi stimulus atau rangsangan. Kedua, Koordinasi Disamping adanya komunikasi dalam menciptakan sinergitas juga memerlukan koordinasi. Komunikasi 
tidak dapat berdiri sendiri tanpa adanya koordinasi seperti yang dinyatakan oleh Hasan bahwasannya dalam komunikasi dibutuhkan koordinasi (Garniwa, 2007).

Jenis hubungan antar stakeholder yang ideal pada saat bekerjasama dapat dibeda-bedakan sesuai kebutuhan. Tingkat yang paling tingggi adalah kolaborasi. Dalam hal ini kolaborasi adalah kerjasama telah terjalin secara resmi dengan bertukar informasi dengan tujuan saling menguntungkan, mengubah aktivitas, risiko, berbagi sumber daya, tanggung jawab, penghargaan dan meningkatkan kapsitas orang lain untuk tujuan bersama. Selain itu, kolaborasi terdapat komitmen waktu yang ekstensif serta tingkat lepercayaan yang tinggi antar stakeholder. Berikut adalah paparan jenis hubungan antar-stakeholder:

a. Pemerintah dengan Akademisi

Pemerintah dengan akademisi perlu meningkatkan jenis hubungan menjadi kolaborasi. Kolaborasi didukung dengan komitmen waktu yang efesien, kepercayaan yang tinggi untuk meneingkatkan kapasitas dan saling berbagi risiko. Hal ini diperlukan untuk membantu pemerintah dalam pengembangan program agar berjalan secara optimal. Akademisi sebagai stakeholder yang merupakan sumber pengetahuan dengan teori maupun konsep yang terbaru dan relevan dapat membantu pemerintah bisa berbagi risiko dengan akademisi dan bersama-sama mencari solusi yang tepat untuk menanganinya (Robert L, Mathis,. dan Jackson, 2002).

b. Pemerintah dengan Bisnis

Pemerintahdan bisnis perlu menjalin kolaborasi dalam hal bantuan modal, pelatih, fasilitas, dan akses untuk mempermudah proses bisnis. Dengan jenis bantuan seperti ini, diperlukan adanya kolaborasi yang baik antara pemerintah dengan bisnis untuk saling bertanggung jawab sehingga mengerti bantuan apa yang harus diberikan dan sesuai dengan kebutuhan.

c. Pemerintah dan Komunitas

Komunitas yang menaungi para pembisis dam pemerintah harus memiliki komitmen waktu yang intensif dan kepercayaan yang tinggi. Karena komunitas merupakan stakeholder yang paling dekat dengan masyarakat yang berada dengan pengelola pisang sale. Diharapkan mereka dapat menjadi penghubung ideal kepada pemerintah dalam kolaborasi. d. Akademisi dengan Komunitas

Jenis hubungan antara akademisi dan komunitas adalah coordinating. Akademisi dan komunitas sesuai dengan peran yang dilakukan masingmasing pihak. Dalam hal ini, akademisi tidak perlu terlalu banyak bersinggungan langsung dengan komunitas, namun tetap harus terjalin hubungan secara formal (saling berbagi sumber daya secara minimal dan komitmen waktu yang sedang) karena komunitas menaungi para pelaku yang ada di daerah pengelola pisang sale.

e. Akademisi dan Bisnis

Jenis hubungan antara akademisi dan bisnis adalah networking, maksudnya adalah hubungan terjalin secara informal. Meskipun hubungan terjalin secara informal, saling bertukar informasi tetap diperlukan untuk mengembangakan program bagi pengelola pisang sale.

f. Komunitas dengan Bisnis

Komunitas dan bisnis perlu meningkatkan hubungan menjadi collaborating karena bisnis merupakan stakeholder yang berkontribusi dalam memberikan bantuan sosialisasi maupun bantuan modal hingga bantuan infrastruktur seperti sanitasi maupun tempat ibadah. Komunitas dalam hal ini sangat memerlukan informasi dari bisnis, hal ini untuk mempermudah proses bisnis.

\subsubsection{Model Quadruple Helix dalam Pengembangan Usaha pisang Sale di Kab. Aceh Tenggara}

Dalam konteks negara Indonesia, untuk mendorong UMKM secara umum di negara ini, maka disusunlah konsep UMKM sebagai salah satu ceruk pasar yang potensial di dunia saat ini. Maka diusunglah model Quadruple Helix untuk menciptakan sinergi dan kolaborasi antara stakeholder bidang UMKM.

Adapun kajian literatur terkait dengan kolaborasi model Quadruple Helix sebagai rujukan dalam hasil penelitian kualitatif antara lain menurut Palmer dan Haryer kolaboras pada dasarnya merupakan kesepakatan formal atau informal dua atau lebih organisasi untuk meningkatkan kompetensinya melalui kombinasi sumber daya yang dimiliki dengan para mitranya (Palmer, 1996). Sedangkan menurut pendapat Kotler, Bowens dan Makens menyatakan bahwa UMKM akan mendapatkan suatu keunggulan bersaing jika masing-masing organisasi yang terlibat dapat berbagi pengetahuan, keahlian, keterampilan dan sumber daya lain (River, 2006). 


\section{Jurnal Ilmiah Ekonomi Islam, 7(02), 2021, 898}

\subsubsection{Permasalahan Pengembangan Usaha pisang Sale di Kab. Aceh Tenggara}

Belum adanya regulasi yang jelas ditingkat kementerian bagi stakeholder UMKM dalam pengembangan khususnya pengelola pisang sale Aceh Tenggara, hal ini membuat dalam pengambil kebijakan yang ada di daerah menjadi bingung untuk mengambil keputusan yang tepat dan pasti untuk pengelola pisang sale tersebut.

Sebenarnya dengan adanya Surat Keputusan (SK) yang mewakili seluruh stakeholder Quadruple Helix sudah cukup untuk menggerakkan sektor pengelola pisang sale ini di Aceh Tenggara. Maka salah satu solusi dari ini adalah menerbitkan Surat Keputusan (SK) yang terdiri dari unsur Quadruple Helix yang menjelaskan apa saja yang terlibat dalam penyelenggaraan pengelola pisang sale dan apa tugastugasnya. Maka salah satu solusi dari penulis ini adalah, supaya pimpinan daerah membuat SK Tim Percepatan pengelola pisang sale yang bertanggung jawab untuk pengembangan penyelenggaraan pengelola pisang sale di Aceh Tenggara.

Terkait masalah pemasaran, menurut para stakeholder dan tim percepatan pengelola pisang sale Aceh Tenggara belum maksimal mempromosikan pisang salenya. Belum terlihatnya flayer maupun iklan yang menyatakan bahwa pisang sale Aceh Tenggara wajib untuk dikonsumsi masyarakat Aceh maupun yang dari luar Aceh.Ini membuktikan bahwa Aceh Tenggara belum all out dalam pelaksaan pengembangan pengelola pisang sale. Maka solusi dai ini adalah agar stakeholeder terutama pemerintah sudah selayaknya menampakkan jati diri sbagai pisang sale yang terenak dan terenyah di dunia. Agar semua orang tahu, baik dari dalam negeri maupun luar negeri, bahwa Aceh Tenggara sangat fokus dan mendukung penuh penyelenggaraan pengelola pisang sale di daerahnya.

Model Quadruple Helix belum bisa dilaksanakan dengan maksimal dalam pengembangan pengelola pisang sale di Aceh Tenggara, karena belum jelasnya definisi dan konsep pengelola pisang sale dikalangan stakeholder sendiri. Selain itu, masalah regulasi yang belum jelas dan belum mempunyai payung hukum yang belum juga membuat stakeholder utama yaitu pemerintah daerah ragu dalam menjalankan pengembangan pengelola pisang sale di Aceh Tenggara. Sedangkam dalam konsep Quadruple Helix, semua stakeholder berperan akti, dalam konsep negara Indoneisa, pemerintah daerah berperan sebagai leader.

Selanjutnya banyaknya kegagalan dalam melakukan strategi pengembangan daerah tujuan pengelola pisang sale disebabkan ada beberapa faktor. Walaupum suatu daerah telah memiliki branding dengan logo slogan yang baik, tetap belum dapat mencapai sasaran disebabkan karena adanya kelamahan yaitu: 1). Hubungan antara strategi pengembangan ekonomi kota, 2). Keterlibatan politik selayaknya dilibatkan secara serius dan dipertahankann dengan berbasis waktu yang panjang, 3). Investasi, 4) awareness yang jelas dari target audience, 5) pengetahuan dari persepsi yang original mengenai kualitas image dari setiap target group, 6). Koordinasi diantara stakeholder yang berbeda-beda $(\mathrm{Gj}, 2007)$.

\subsubsection{Model Pengembangan Usaha pisang Sale di} Kab. Aceh Tenggara

Belum adanya regulasi yang jelas ditingkat kementerian dan pemerintah bagi stakeholder dalam pengembangan UMKM pengelola pisang sale, hal ini membuat pengamil kebijakan yang ada di daerah menjadi bingung untuk mengambil keputusan yang tepat dan pasti untuk pengembangan UMKM pengelola pisang sale.

Terkait masalah pemasaran, menurut para stakeholder Kab. Aceh Tenggara masih belum maksimal mempromosikan pisang sale. Belum terlihanya iklan maupun flayer yang menyatakan bahwa Kab. Aceh Tenggara menjadi salah satu pisang sale yang terenak, terbaik dan terlaris di dunia, yang ada promosi pisang sale biasa saja. Ini membuktikan bahwa Kab. Aceh Tenggara belum all out dalam pelaksanaan pisang sale. Maka solusi dari ini adalah, agar stakeholder terutama pemerintah untuk sudah selayaknya menampakkan jati diri sebagai pengelola pisang sale Kab. Aceh Tenggara di dunia. Agar semua orang tahu, baik dari dala, ,aupun luar negeri, bahwa Kab. Aceh Tenggara sangat fokus dan mendukung penuh penyelenggaranpengelola pisang sale didaerahnya. Selanjutnya untuk mendukung akses, para stakeholder harus berupaya ekuat tenaga agar jalur udara diperbanyak dan dilengkapi. Para stakeholder harus berupaya sekuat tenga agar jalur udara diperbanyak dan dilengkapi.

Model Quadruple Helix belum bisa dilaksanakan dengan maksimal dalam pengembangan UMKM pengelola pisang saledi Kab. Aceh Tenggara, karena belum jelasnya definisi dan konsep pengembangan 


\section{Jurnal Ilmiah Ekonomi Islam, 7(02), 2021, 899}

UMKM pengelola pisang sale dikalangan stakeholder sendiri. Selain itu, masalah regulasi yang belum jelas dan mempunyai payung hukum yang belum juga membuat stakeholder utama yaitu pemerintah daerah ragu dalam menjalankan pengembangan UMKM pengelola pisang sale di daerahnya. Sedangkan dalam konsep Quadruple Helix, semua stakeholder berperan aktif, dalam konsep negara Indonesia, pemerintah daerah sebagai leader.

\section{KESIMPULAN}

Terdapat cara tersendiri untuk mengetahui arah stakeholder pada sebuah tujuan untuk pengelola pisang sale. Tidak hanya sebatas kualitas pisang sale akan tetapi juga pandangan terhadap kebersian, estetika yang berkaita dengan kondisi pisang sale. Para stakeholder dan masyarakat luas sangat berperan penting untuk mengembangkan usaha pisang sale. Akademisi, berperan sebagai mendukung untuk memasarkan pisang sale kepada masyarakat dan akademisi juga mempromosikan pisang sale di sosial media. Karena pelaku usaha pisang sale keterbatasan memiliki hp android. Pemerintah yang berperan yaitu Kantor Dinas UKM dan Koperasi dengan mengutuskan pengelola pisang sale ke Banda Aceh apabila ada pelatihan, tujuannya adalah pada saat di Banda Aceh pengelola pisang sale diajarkan bagaimana memasak pisang sale agar renyag, membungkus pisang sale dengan cara cepat dan tepat. Bisnis berperan turut memberikan kualitas produk terbaik kepada masyarakat dan membuat ide-ide ataupun inovasi varian rasa pisang sale untuk kedepannya.

\section{REFERENSI}

Anggraini, D., \& Nasution, S. (2013). Peranan Kredit Usaha Rakyat (Kur) Bagi Pengembangan Umkm Di Kota Medan (Studi Kasus Bank Bri). Jurnal Ekonomi Dan Keuangan, 1(3), 14879.
Barus, D. S. (2019). Strategi Pengembangan Digital Entrepreneurship Usaha Mikro Kecil Menengah (UMKM) dengan menggunakan Model Penta Helix.

Garniwa, S. dan. (2007). Perilaku Organisasional. Graha Ilmu.

Gj, K. M. A. (2007). Ashworth Gj, Partner in Coffeshop, Canal and Commerce: Marketing in city of Amsterdam. 24(1).

Moelong. (2016). Metode Penelitian Kualitatif. PT Remaja Rosdakarya.

Najiyati, S. dan S. R. T. S. (2011). Sinergitas Instansi Pemerintah Dalam Pembangunan Kota Terpadu Mandiri (The Synergy of Goverment Institutions in The Transmigration Urban Development). Ketransmigrasian.

Palmer, A. J. A. R. M. (1996). Relationship Marketing: A New Paradigm for the Trave and Tourism Sector?(Journal of Vaction Marketing.

Praswati, A. N. (2017). Perkembangan Model Helix dalam Peningkatan Inovasi. Seminar Nasional Riset Manajemen \& Bisnis.

River, M. for H. and T. (4d ed). (Upper S. (2006). Marketing for Hospitality and Tourism (4d ed). (Upper Saddle River. Bowen, John T., Author.

Robert L, Mathis,. dan Jackson, J. H. (2002). Manajemen Sumber Daya Manusia. Salemba.

Suci, Y. R. (2017). Pekembangan UMKM (Usaha Mikro Kecil dan Menengah di Indonesia). Jurnal Ilmiah Cono Ekonomos, 6(1).

Sugiyono. (2018). Metode Penelitian Kuantitatif Kualitatif dan $R \& D$. Alfabeta.

http://datakumkm.acehprov.go.id/index.php/umkm. (2021).

http://www.depkop.go.id/data-umkm. (2021).

https://keuangan.kontan.co.id. (2020, January 23). www.bps.go.id. (2021, January 28). 